\title{
Article \\ Use of a Negative-Pressure Wound Dressing to Prevent Surgical Site Complications after Revision Knee Arthroplasty-A Randomized Controlled Trial
}

\author{
Christoph Deborre ${ }^{\dagger}$, Afoma Ezissi ${ }^{\dagger}$, Max Jaenisch $* \mathbb{D}$, Mona Khoury, Christof Burger, Thomas Martin Randau (D) \\ and Hendrik Kohlhof
}

check for

updates

Citation: Deborre, C.; Ezissi, A.; Jaenisch, M.; Khoury, M.; Burger, C.; Randau, T.M.; Kohlhof, H. Use of a Negative-Pressure Wound Dressing to Prevent Surgical Site

Complications after Revision Knee Arthroplasty-A Randomized Controlled Trial. Appl. Sci. 2021, 11, 9102. https://doi.org/10.3390/ app11199102

Academic Editor: Johann Zwirner

Received: 12 August 2021

Accepted: 21 September 2021

Published: 30 September 2021

Publisher's Note: MDPI stays neutral with regard to jurisdictional claims in published maps and institutional affiliations.

Copyright: (c) 2021 by the authors. Licensee MDPI, Basel, Switzerland. This article is an open access article distributed under the terms and conditions of the Creative Commons Attribution (CC BY) license (https:// creativecommons.org/licenses/by/ $4.0 /)$.
Department of Orthopaedics and Traumatology, University Hospital Bonn, Venusberg Campus 1, 53127 Bonn, Germany; chrisdeborre@gmx.de (C.D.); aezissi@googlemail.com (A.E.); mona.khoury@ukb.uni-bonn.de (M.K.); christof.burger@ukb.uni-bonn.de (C.B.); thomas.randau@ukb.uni-bonn.de (T.M.R.); hendrik.kohlhof@ukb.uni-bonn.de (H.K.)

* Correspondence: max.jaenisch@ukbonn.de; Tel.: +49-151-4403-8553

+ Authors contributed equally to this work.

Featured Application: The following work is aimed to further improve wound management in complex cases of re-vision knee arthroplasty.

Abstract: The aim of this study was to determine if a negative pressure wound therapy (NPWT) system can facilitate wound healing and withstand mechanical stress owing to the high range of motion of the knee joint in total knee arthroplasty. The benefits of NPWT include aiding wound granulation and a reduction in wound edema and secretion; our goal is to investigate its benefits in primary wound closure. Within an eight-day duration of treatment, we compared standard wound dressing (gauze and compression) with the disposable NPWT system (PICO) ${ }^{\mathrm{TM}}$. A total of 79 patients were recruited in a controlled, randomized, prospective, single-institution clinical trial. A total of 40 patients were allocated to the study group and 39 to the control group. In terms of blood loss and infection parameters, there was no significant difference between both groups. In the NPWT group, we determined a significant reduction in wound edema but none in wound secretion. While the NPWT dressings survived the mechanical effects of movement during postoperative physiotherapy, conventional compressive dressings were often renewed. Even though the risk factors that could lead to delayed wound healing were reduced in the test group, we could not identify any significant difference pertaining to delayed wound healing that required surgical treatment.

Keywords: knee; revision; arthroplasty; negative-pressure wound dressing

\section{Introduction}

Elective total knee arthroplasty (TKA) is indicated in cases where conservative medical interventions have failed. Osteoarthritis is the most significant diagnosis leading to the replacement of knee joints [1]. TKA can reduce pain and increase functionality and quality of life in patients undergoing such a therapy [2-4]. With a steadily increasing population age [1], an improvement in surgical techniques such as accuracy in alignment [5], and an overall success in relieving pain and boosting functionality in the elderly [6], the rate of utilization of TKA has increased over the years. Although the rate of periprosthetic joint infections (PJI) after TKA is low, the effects of such an infection on both the patient and the institutions catering to them can be tremendous. Stringent budgets due to the current economic atmosphere [7] have resulted in an ever-mounting need to reduce costs and have led to the implementation of several perioperative interventions. These aim to facilitate a more efficient postoperative analgesia, early functional recovery through early rehabilitation, and reduced length of stay (LOS) $[8,9]$. Therefore, the prevention of PJI or surgical site infections (SSI) is vital in achieving these goals. 
There are a vast number of available dressing materials and procedures intended for the treatment of chronic wounds or wounds healing by secondary intention. One such procedure is the application of negative pressure wound therapy (NPWT) [10-13]. NPWT has greatly influenced the outcome of wounds while reducing the LOS, material cost, and frequency of wound dressing changes, thereby saving personnel resources [11,14]. Its ability to prevent infection or dehiscence in closed surgical incisions has been described [15]. The mechanism of action of NPWT lies in its ability to speed up wound healing by adapting wound edges, thus making the wound surface area smaller, increasing vascularization of the wound bed, and inducing epithelial cell growth. It aids in wound cleansing by removing accumulated wound fluids [16-19]. Since its discovery, the use of NPWT has been sporadically described [20]. The indication for use of NPWT extended to acute wounds [21]; recently, smaller, more portable devices were introduced to address the issue of patient mobility. This, combined with its simplified application, has resulted in a reduced LOS as its use allows wound management to occur on an outpatient basis [22,23].

Today, ultraportable NPWT systems are available. One such device $\left(\mathrm{PICO}^{\mathrm{TM}}\right.$, Smith \& Nephew Medical Ltd., Hull, UK) is an innovative, lightweight, single-use device delivering a continuous vacuum pressure of $80 \mathrm{mmHg}$. Being canister-free, $20 \%$ of the wound exudate is absorbed by the dressing, while $80 \%$ evaporates through its semipermeable adhesive foil [24]. The dressing comes in assorted sizes, which can be directly placed on shallow lesions. Foam or gauze filters are available for wounds with deeper tissue damage. We chose this system because of its ease of application which makes it ideal for use not only in fast-track surgery but in community settings as it can, in low or moderate exuding wounds, remain on the wound for a maximum of 7 days. Being disposable, it is an ideal option for outpatients in need of NPWT and allows for early discharge from acute hospitals [22,25]. This study found a significant decrease in wound edema, a known contributing factor to PJI and SSI, after application of the PICO-System.

\section{Materials and Methods}

This single-centered, prospective-randomized, parallel-controlled, clinical study was designed to compare the effects of incisional NPWT as delivered by the PICO ${ }^{\mathrm{TM}}$ system against standard compressive dressings in 66 patients after elective total knee arthroplasty over an eight-day period. The study protocol and subject consent forms were reviewed and approved by the Ethics Commission of the Faculty of Medicine at the Rheinischen Friedrich Wilhelms University, Bonn. Ethics approval no. 322/14 on 11 December 2014. This trial was conducted in adherence to good clinical practice and in compliance with applicable regulatory requirements in accordance with the provisions of the Declaration of Helsinki.

Patients with indications for TKA were recruited into the study after written and verbal information had been provided to them by the principal investigator or one of his delegates.

A signed agreement was acquired from all consenting patients meeting the eligibility criteria (Table 1.)

Table 1. Eligibility and exclusion criteria.

\begin{tabular}{ll}
\hline Eligibility Criteria & Exclusion Criteria \\
\hline Planned total knee arthroplasty & Patients younger than 18 years of age \\
\hline Planned one-stage knee exchange arthroplasty & Anticipated lack of compliance \\
\hline Planned two-stage exchange arthroplasty & $\begin{array}{l}\text { Indication of isolated retro-patellar resurfacing, inlay revision or } \\
\text { ligamental balancing }\end{array}$ \\
\hline $\begin{array}{l}\text { Possibility of postoperative application of both dressing } \\
\text { methods. }\end{array}$ & $\begin{array}{l}\text { Tested infection of implanted knee endoprosthesis at time of } \\
\text { screening }\end{array}$ \\
\hline & Indication for tumor prosthesis \\
\hline & Medical history of hemophilia \\
\hline
\end{tabular}


Using a pseudo-random generator, a total of 79 patients were pseudonymized and allocated either to the study or control group. A total of 40 patients were assigned to the study group (NPWT) and 39 to the control group (standard dressing). Only postoperative wound therapy and not the surgical intervention were subject to randomization.

On admission, each patient underwent a routine physical examination. A detailed medical history, including important previous illness, premedication, and vital parameters as well as laboratory tests, were recorded.

So as not to influence the outcome of this study, only patients indicated for primary knee arthroplasty, those with planned one-stage exchange arthroplasty following mechanical loosening of the implant, and those with planned two-stage exchange arthroplasties prior to the scheduled implementation of a new prosthesis were considered.

All patients were operated per clinic standard and received intraoperative single shot prophylactic antibiotics as well as two surgical vacuum drains. In the operating theatre, a sterile gauze dressing was applied to of patients' wounds in both groups, followed by a non-sterile, compressive dressing encompassing the entire operated limb. This dressing remained in place until the second postoperative day, when the first wound assessment was made.

Due to the nature of this trial, a blinded study was not feasible. For primary outcome assessment, wounds were observed by one of three certified wound care managers using a semi-quantitative, semi-qualitative approach. To minimize error and attain consistency, the responsible wound managers were from a different ward and were not involved in the daily care of the subjects. Prior to assessment and in the absence of the wound care manager, all dressing materials were removed and discarded by the on-duty nurse responsible for the participant to achieve a semi-blinded assessment of the wound. A wound assessment chart was designed, and for each item assessed, a numerical score was ascribed (see Table 2).

Table 2. Wound assessment (WA) chart and numerical scores for observation of wound exudate, wound character, wound edge and wound surrounding. (a) Wound exudate: 1 none/minimal, 2 moderate, 3 excessive exudates; (b) Character of wound exudate: 1 no secretion, 2 sanguinous, 3 serous, 4 haemoserous, 5 purulent; (c) Odor: 1 none/normal 2 malodor; (d) Wound character: 1 primary, 2 predominantly primary, 3 large defects/wound healing disorder, 4 predominant defects/wound healing disorders. (e) Wound color: pink tissue (epithelializing), red (granulating), yellow (fibrinous/sloughy), black (necrotic) 1 pink, 2 pink-red, 3 red, 4 red-yellow, 5 yellow, 6 black-yellow-red, 7 black-yellow, 8 black; (f) Wound edge color: 1 normal, 2 cyanotic, 3 red, 4 pale; (g) Wound infiltration: 1 normal, 2 soft, 3 hard; (h) Wound edge edema: 1 little/none, 2 moderate, 3 excessive; (i) Wound edge color: 1 normal, 2 cyanotic, 3 pale, 4 red (infection, erysipelas, phlegmon); (j) Wound environment edema: 1 normal, 2 local, 3 generalised; (k) Temperature: 1 normal, 2 slightly warm, 3 excessively warm; (l) Eczema: 1 none, 2 slight irritation, 3 allergy, 4 congestions; (m) Secondary lesions caused by dressing: 1 none, 2 blisters, 3 abrasions.

\begin{tabular}{llll}
\hline & Patient ID & & 2. WA \\
\hline & 1. WA & 1 & \\
\hline (a) Wound exudate & 1 & 1 & 1 \\
(b) Character of wound exudate & 1 & 1 & 1 \\
(a) Drainage secretion & 1 & 1 & 1 \\
(b) Secretion character & 3 & 1 & \\
(c) Odour & 1 & 3 & \\
(d) Wound character & 2 & 1 & \\
(e) Wound color & 3 & 2 & \\
(f) Wound edge & 1 & 2 & \\
(g) Wound infiltration & 2 & 2 & 1 \\
(h) Wound edge edema & 2 & 3 & 1 \\
(i) Wound edge color & 2 & 2 & 1 \\
(j) Wound environment edema & 2 & 1 & 1 \\
(k) Temperature & 2 & 1 & 1 \\
(l) Eczema & 1 & & \\
(m) Secondary lesions caused by dressing & 1 & 1 \\
\hline
\end{tabular}

Comments:

Wound Manager Signature: 
On the second postoperative day, standard compressive dressings and surgical vacuum drains were removed, and according to in-house standards, a laboratory test determining blood cell count, serum creatinine, and electrolytes was carried out. After wound assessment, NPWT and an antithrombotic compressive stocking were applied over the dressing in the study group. Standard compressive dressings were applied in the control group. The dressings were administered by the on-duty nurse and not by the wound manager.

This procedure was repeated on the fifth (second dressing change/first NPWT change) and eighth (third dressing change) postoperative days, respectively. The study ended on the commencement of the third wound inspection on the eighth postoperative day. Hereafter, all further dressings were in the form of standard compressive dressings.

During the trial, all patients were subjected to routine post-surgical recovery protocol.

For statistical analysis, data were exported into GraphPad Prism version 5.04 for Windows (GraphPad Software, San Diego, CA, USA, www.graphpad.com (accessed on 11 August 2021)). Data for primary hypothesis (edema and secretion) was analyzed by group comparison using the Mann-Whitney U test. Differences were assumed to be significant with $p<0.05$. All other parameters were assessed \%o by bulk analysis using the Kruskal-Wallis test or ordinary one-way ANOVA, using Dunn's or Bonferroni's post hoc test with adjustment for multiple comparisons.

\section{Results}

Patients were recruited between September 2014 and June 2016. In this time, a total of 113 patients were screened for inclusion in this study. Of these, a total of 34 patients were excluded for not meeting eligibility criteria: nine due to an anticipated deficit in compliance, 14 due to surgical intervention other than total knee arthroplasty, four denied consent. Seven patients were excluded due to planned changes in therapy, as preoperative evidence of infection in the knee joint was verified and no further data were collected on these patients. Of the 79 randomized patients, 66 partook in the study, although 40 were initially allocated to the NPWT group and 39 to the control group.

In the NPWT group, six patients were excluded after randomization, resulting in a total of 34 participating patients. They were excluded for the following reasons: two withdrew consent, one developed instability of the prosthetic joint and required revision, one each incurred cardiac and neurologic ischemic complications and were referred to cardiologic and neurologic departments for further treatment, and one was discharged before intended study end. No participant in this group incurred secondary wound complications such as blistering caused by the applied dressing.

In the control group, a total of 32 patients concluded the study; seven were excluded after randomization for the following reasons: three underwent revisions due to either periprosthetic fracture, acute infection of the knee joint, or the development of intraarticular hematoma-factors not ascribed to the chosen dressing. One patient had to undergo revision due to the development of wound necrosis, a factor that could possibly be attributed to the chosen wound dressing. One was excluded after ischemic myocardial complications and was also referred to the cardiologic department, while two patients were discharged prior to the study's conclusion (Figure 1).

The mean age of patients in the NPWT group was 67.5 years (SD 10.6, range $=42-85$ years) as opposed to 63.6 years (SD 16.4, range $=23-87$ years) in the control group. Both groups were well balanced, showing no relevant difference relative to gender and age. Both groups were similar in relation to most preexisting risk factors.

As for the primary hypothesis that NPWT would reduce the rate of primary wound infections, we must say that we had no primary infections in either group and can therefore not state a benefit for the NPWT. We also saw no significant differences in the scoring for the amount or character of the secretion of the wound or from the drains at any of the three wound observation time points (see Figure 2). In both groups, most patients had 
grade 1-2 levels of exudate and there was no significant difference $(p=0.13)$ in quantity of secretion in either group.

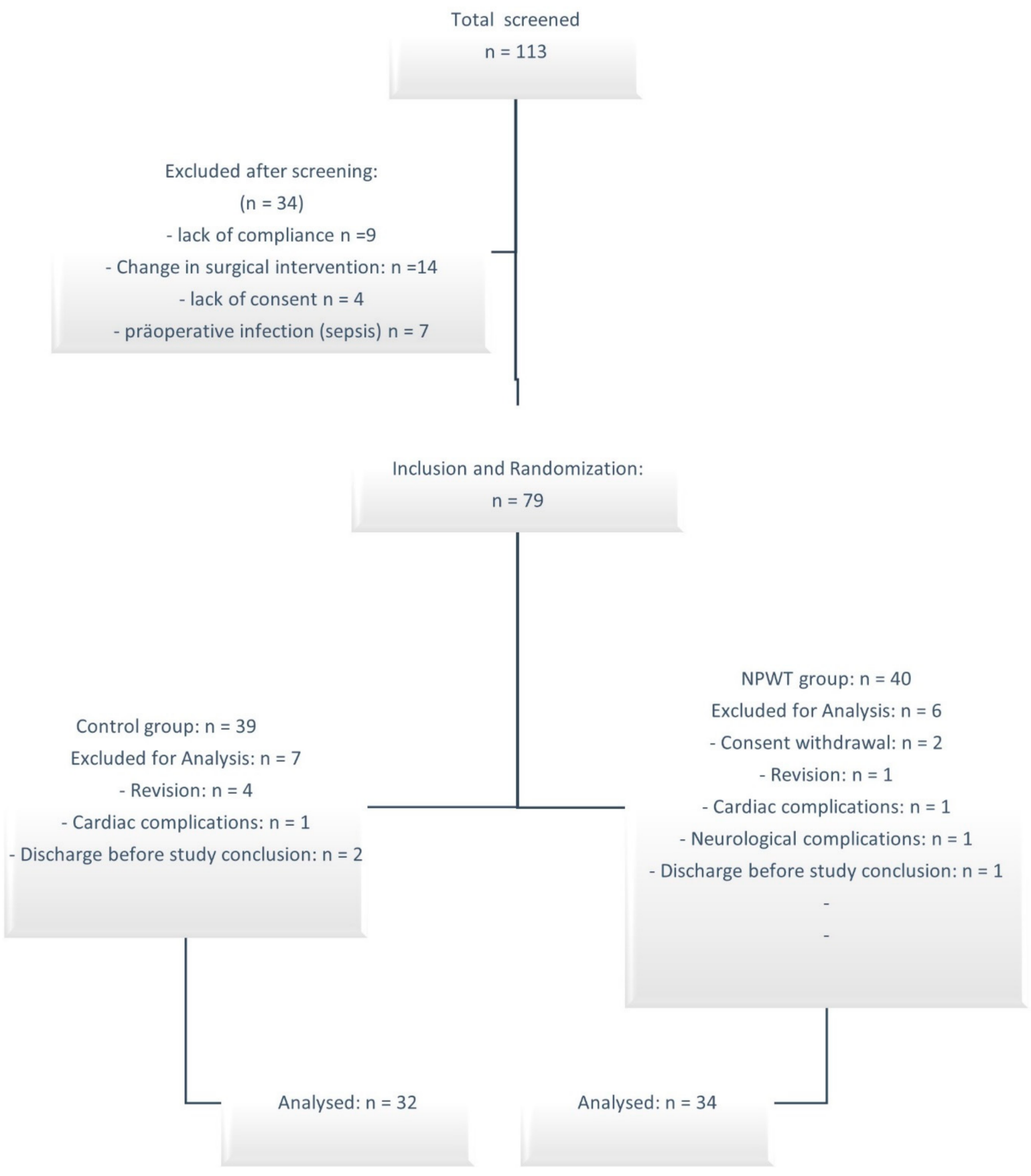

Figure 1. Exclusion patients.

The only difference was seen regarding early wound edema, which was significantly reduced at first dressing change in the NPWT group $(p=0.017)$ (Figure 3).

As for secondary objectives, we found that after physiotherapy, which included active and passive movement of the knee in free range of motion as well as the daily use of the continuous passive movement machine, no additional dressing change was required in the NPWT group. In the study group, however, conventional dressings often became loose after frequent movement, thus making the application of a new compressive dressing necessary. This led to more hands-on time for nurses and staff. 


\section{Secretion Score}

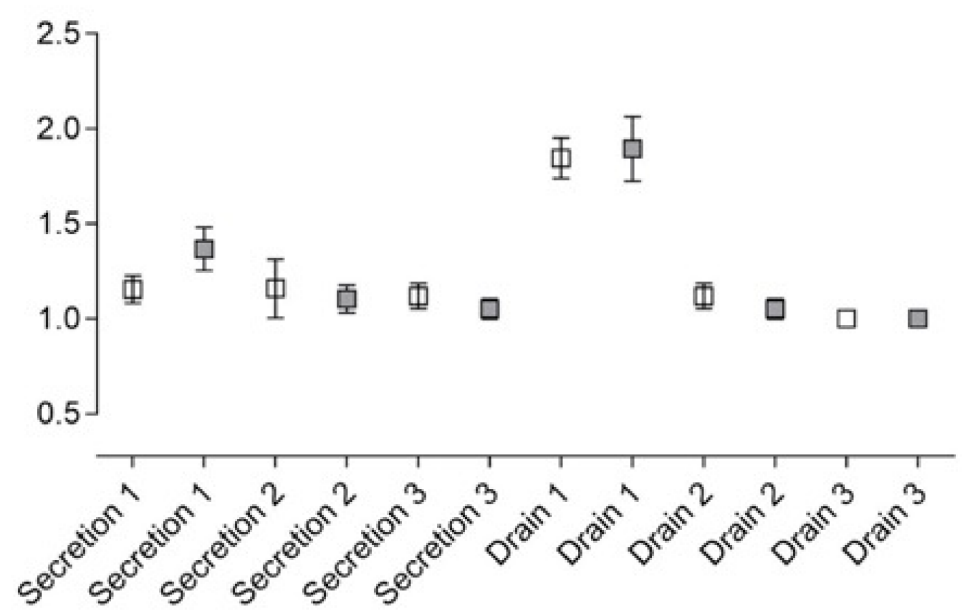

Figure 2. Secretion quantity score from wound and drainage site over the three observation points. Shown is the mean with error bars indicating $95 \%$ confidence interval.

\section{Healing \& Edema}

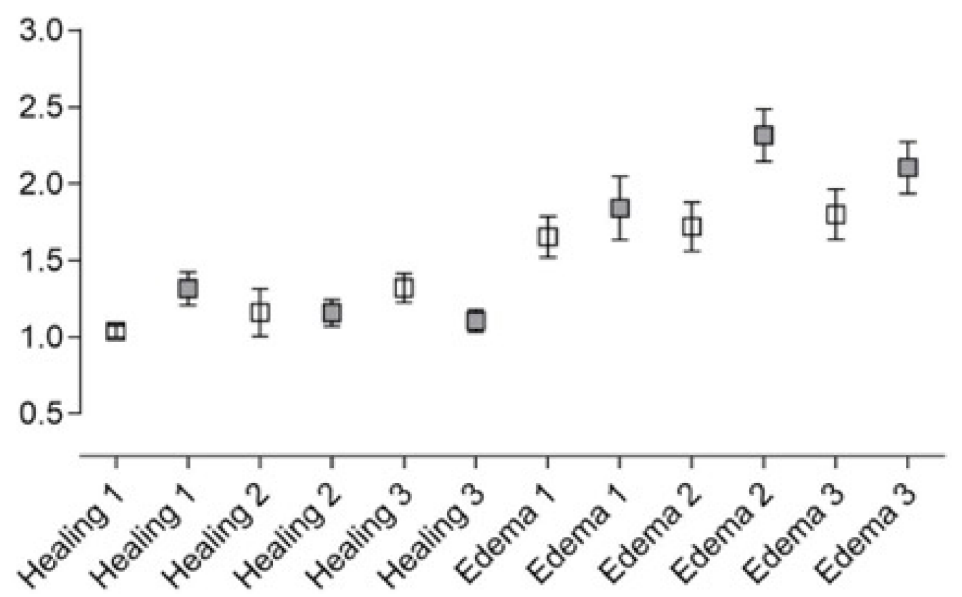

Figure 3. Edema score from wound and wound edge over the three observation points. Shown is the mean with error bars indicating $95 \%$ confidence interval.

We saw one superficial necrosis of the wound edge in the control group, but no secondary wound complications such as blistering or adverse reaction to the adhesive in the NPWT group (Figures 4 and 5).

All other data acquired were analyzed by ANOVA and corrected for multiple comparisons. We saw no differences between the treatment groups in any of the parameters assessed, in neither lab stats nor local wound effects.

Wound length differed slightly in both groups with a mean length of $17.66 \mathrm{~cm}$ (standard deviation $(\mathrm{SD}) 3.2$, range $=14-29 \mathrm{~cm}$ ) in the study group and $20.0 \mathrm{~cm}(\mathrm{SD} 5.2$, range $=15-34 \mathrm{~cm})$ in the control group but with no statistical significance $(p=0.07)$. We saw no difference in blood loss between the two groups, as measured by postoperative hemoglobin concentration (Figure 6). The same was true for the leukocyte count, c-reactive protein, and serum creatinine. 


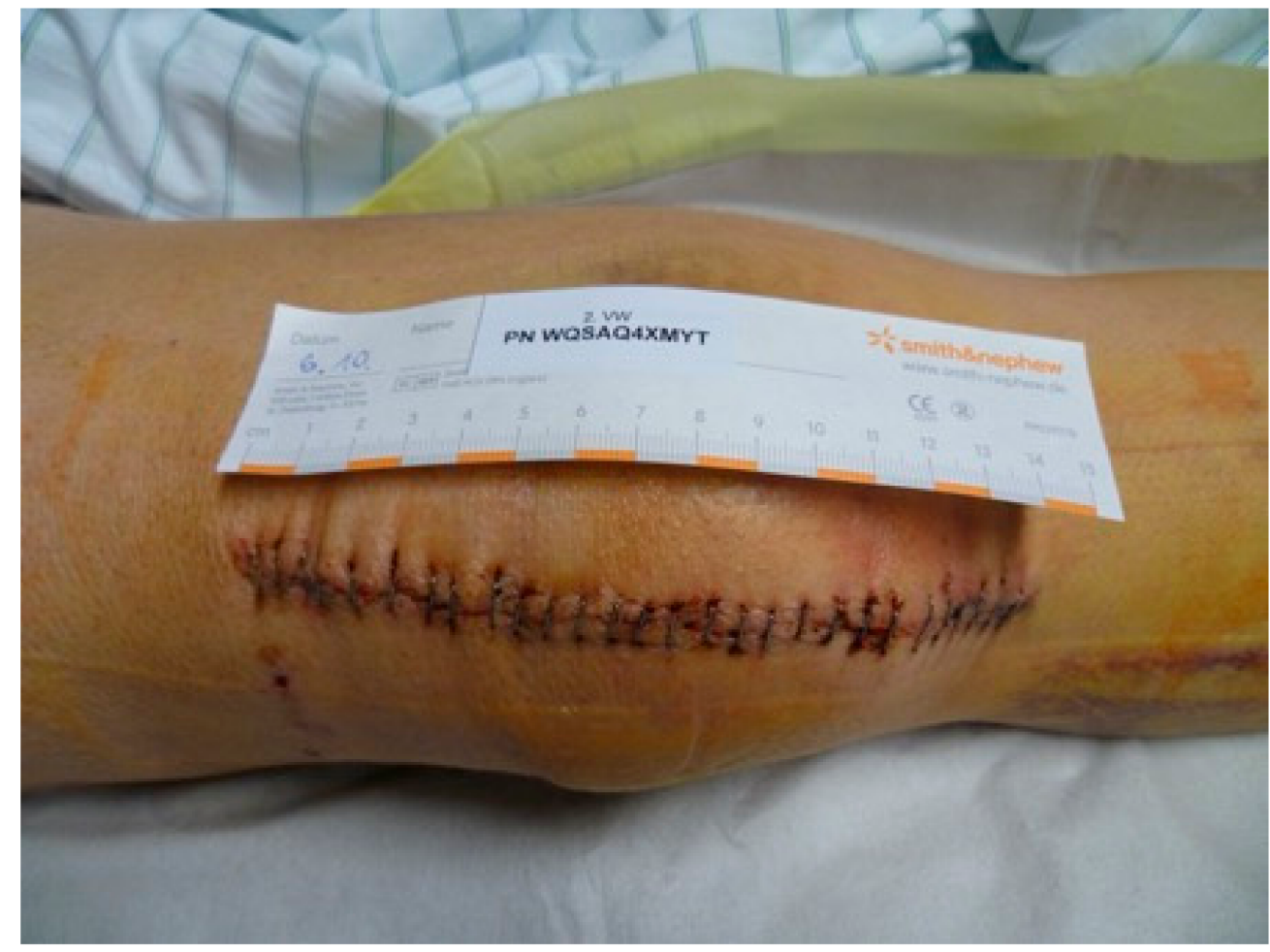

Figure 4. Study group: second dressing change (fifth postoperative day).

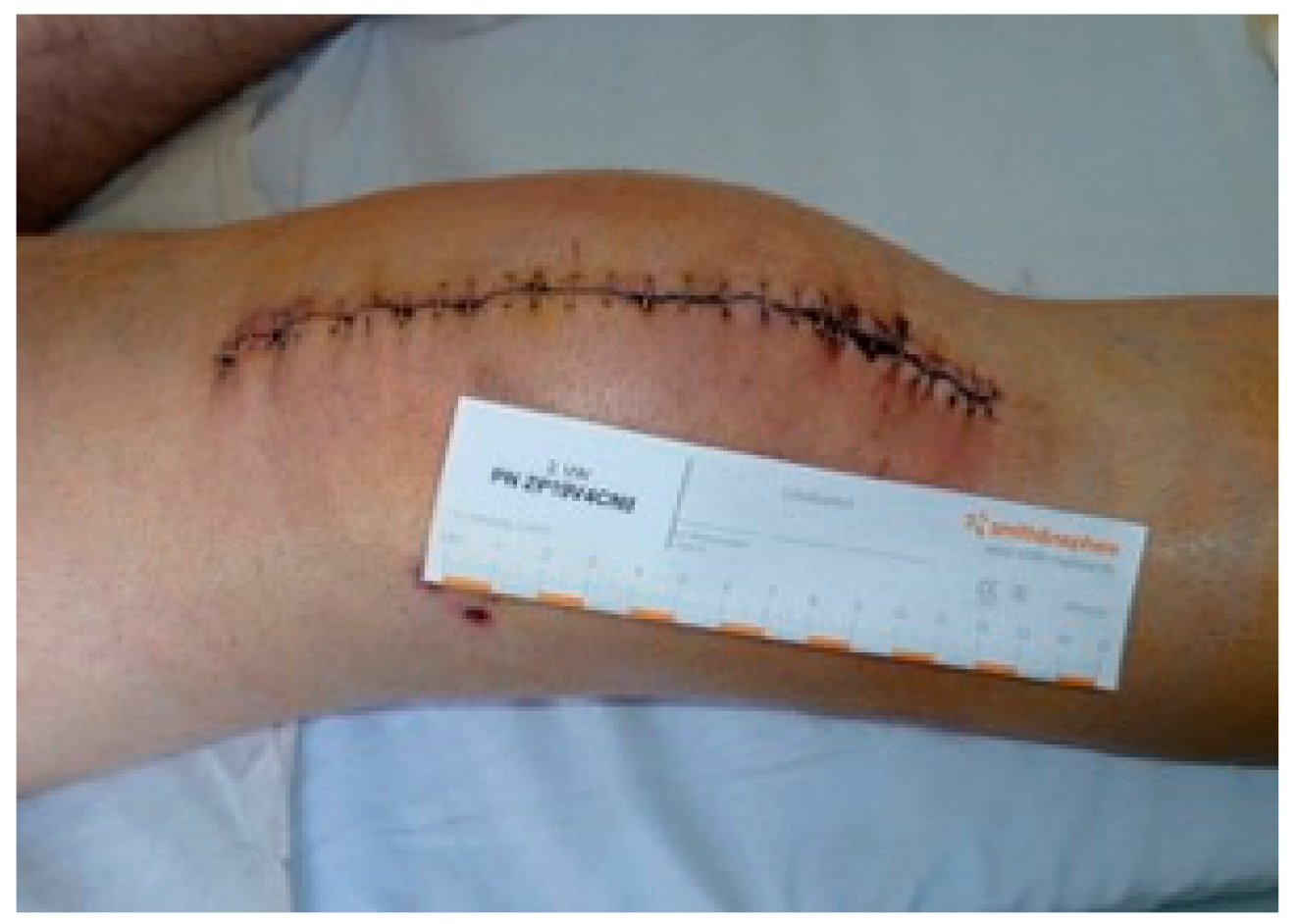

Figure 5. Control group: second dressing change (fifth postoperative day). 


\section{Hemoglobin}

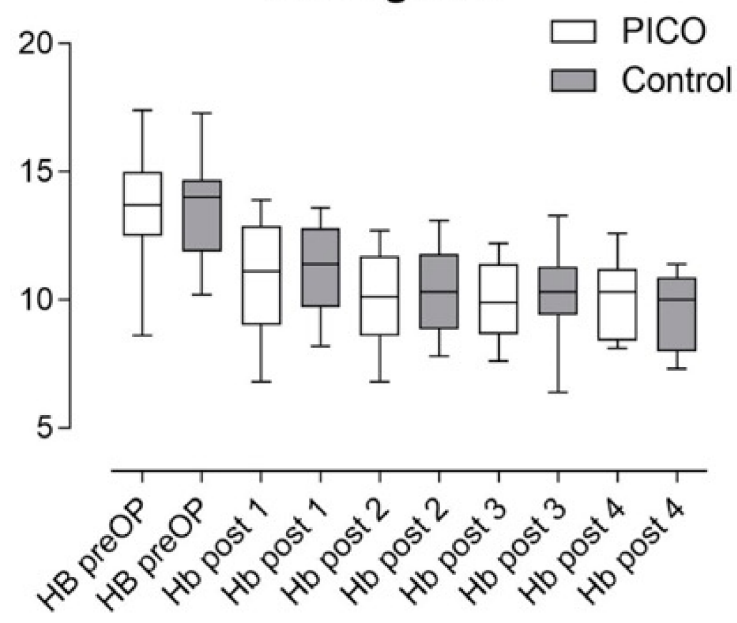

Figure 6. Hemoglobin change over observation time. Shown is the mean with error bars indicating $95 \%$ confidence interval.

\section{Discussion}

The primary aim of this study was to show a possible reduction in the rate of wound infections following TKA. As neither group incurred primary wound infections, this study cannot state a definite benefit of NPWT over conventional wound dressing methods. However, a reduction in wound edema, which is a significant outcome of this analysis, could lead to the prevention of PJI in patients receiving elective TKA. Furthermore, we established that patients in the NPWT group received fewer dressing changes due to slippage after postoperative physiotherapy regimens, leading to a considerable reduction in person hours and dressing materials.

Despite advances in surgery resulting in better outcomes for patients after TKA, the threat of wound complications leading to wound dehiscence or deep prosthetic infection is still a factor an orthopedic surgeon wishes to reduce.

Due to the lack of good clinical evidence comparing different types of wound dressings and their effects on SSI, LOS, and cost efficiency, the National Institute for Health and Clinical Excellence (NICE, UK) has suggested further research in this area [26]. A study focus on the use of chronic wound dressings in acute wounds is therefore encouraged. With the known positive effects of NPWT in the healing of chronic and acute wounds, it was therefore paramount to access the benefits of such a system in the prevention of wound complications.

PJI is a feared complication that results in harrowing and severe situations for the patient and leads to great financial burdens to payment systems and hospitals administering to these patients [27]. PJI inevitably leads to surgical revision of infected joints and may result in removal of the prosthesis with severe loss of function and mobility. Studies have shown that the rate of PJI following primary TKA ranges between $0.5 \%$ and $5 \%[28,29]$. In revision knee surgery, the risk is further increased. Impaired primary wound healing can be linked to PJI-amongst others, intrinsic factors such as rheumatoid arthritis [30], diabetes, use of steroids, obesity as well as local factors such as poor vascular perfusion and lymphedema are known to lead to problems in primary wound healing and subsequently in some cases to PJI [31]. Galat et al. [32] showed that patients with wound healing problems were at a significantly greater risk for further complications. Other studies suggest that SSI also prolongs the length of stay after orthopedic surgery [33]. Our study found no significant reduction in wound infection in either group as none of the included patients developed a primary infection during the trial.

Wound dressings play a significant role in postoperative patient care. Not only should they create a milieu promoting tissue growth, but they should also protect newly grown tissue from damage. Adequate dressings minimize infection to the wound by being 
impermeable to bacteria [34] while at the same time being absorbent, especially in wounds with high exudate levels. Prolonged wound drainage has been associated with an increase in LOS and postoperative morbidity in patients after TKA [35]. We observed a significant reduction in early wound edema and a tendency toward reduced secretion, both of which are known factors leading to secondary wound complications, although the latter was not statistically significant. Their reduction might therefore avert such difficulties.

Considering the anatomy of the knee, it was also important to verify the resilience of such a system as it would have to function sufficiently despite a wide range of repetitive movement in the knee joint following postoperative physiotherapeutic protocols. Karlakki et al., in their study on the effects of incisional NWPT in hip and knee arthroplasty, described a significant reduction of dressing changes while using the PICO system [25]. It is our experience, and this study shows, that conventional compressive dressings tend to loosen and slide after prolonged physiotherapy, making the application of new dressings after such procedures necessary. In contrast, and in accordance with their findings, the PICO system did not require renewal after such procedures and showed no signs of loss of pressure, thus reducing the necessity of frequent dressing changes. These findings make the application of such a system generalizable to anatomical areas with less range of motion.

A study performed by Howell et al. on the effect of NPWT using the VAC Therapy (Kinetic Concepts Inc., San Antonio, TX, USA) in the immediate postoperative period after total knee arthroplasty had to be cut short due to the occurrence of blister formation in $63 \%$ of the study group. In their study, blisters were observed at the skin-sponge boundary and attributed to an increase in friction generated during postoperative exercises. The authors encouraged further research in the reduction of blister formation while utilizing NPWT [36]. Besides its portability and ease of application, PICO was chosen as it also promises to distribute pressure evenly over the applied surface, thus decreasing lateral and shear stress over sutures, a possible mechanism that could lead to the occurrence of blisters. Blister formation was not a complication observed in our trial. Furthermore, none of the 34 participants complained of an increase in pain regarding the application of the system, during dressing changes, or throughout the duration of the system's application. Patients could shower with the system in place, and mobility was not impaired. Limitations to this study are its small sample size and the fact that the rate of wound healing complications or PJI after TKA is generally low. Additionally, lacking standardized authenticated methods of assessment, wound healing criteria were based on semi-quantitative and semi-qualitative observation. Furthermore, observed complications such as deep hematoma were not ascribed as dependent on the chosen dressing in either group but because of the performed surgery. PICO dressings can be applied on a wound for a maximum of seven days without dressing change. To allow for better wound observation, dressings were changed every three days so that only definite statements for this time frame can be made.

\section{Conclusions}

The benefits of the use of chronic wound dressings providing negative wound pressure are widely known. This study examined the effects of negative wound pressure therapy on acute, primarily closed incisions following TKA. A significant reduction in early wound edema was noted, thereby promising benefits in the prevention of SSI. We encourage further studies to determine the efficacy of such a system on critical wounds, such as is the case in open reduction and internal fixation in distal ankle fractures, particularly distal fibula fractures.

Author Contributions: Conceptualization, H.K., C.D., A.E.; methodology, C.B., T.M.R.; software, M.J., A.E., C.D.; validation, T.M.R., H.K.; formal analysis, T.M.R., J.M.; investigation, A.E., C.D., M.K.; resources, C.B., H.K.; data curation, C.D., T.M.R., M.J.; writing-original draft preparation, C.D., A.E.; writing-review and editing, M.J., M.K., C.D.; visualization, M.J., T.M.R.; supervision, C.B., H.K.; project administration, C.B., H.K.; funding acquisition, T.M.R., A.E. All authors have read and agreed to the published version of the manuscript. 
Funding: E.A. received a personal grant from Smith and Nephew, London, Great Britain (N-014.0099).

Institutional Review Board Statement: Study protocol and subject consent forms were reviewed and approved by the Ethic Commission of the Faculty of Medicine at the Rheinischen Friedrich Wilhelms University, Bonn. This trial was conducted in adherence to Good Clinical Practice and in compliance with applicable regulatory requirements in accordance with the provisions of the Declaration of Helsinki.

Informed Consent Statement: Informed consent was obtained from all subjects involved in the study.

Data Availability Statement: Data are available on request due to privacy restrictions.

Conflicts of Interest: E.A. received a personal grant from Smith and Nephew, London, Great Britain.

\section{References}

1. Carr, A.J.; Robertsson, O.; Graves, S.; Price, A.J.; Arden, N.K.; Judge, A.; Beard, D.J. Knee replacement. Lancet 2012, 379, 1331-1340. [CrossRef]

2. Singh, J.A. Epidemiology of Knee and Hip Arthroplasty: A Systematic Review §. Open Orthop. J. 2011, 5, 80. Available online: https:/ / benthamopen.com/FULLTEXT/TOORTHJ-5-80 (accessed on 20 February 2017). [CrossRef] [PubMed]

3. Ethgen, O.; Bruyère, O.; Richy, F.; Dardennes, C.; Reginster, J.-Y. Health-Related Quality of Life in Total Hip and Total Knee Arthroplasty. J. Bone Jt. Surg. Am. 2004, 86, 963-974. [CrossRef] [PubMed]

4. March, L.M.; Cross, M.J.; Lapsley, H.; Tribe, K.L.; Courtenay, B.G.; Brooks, P.M. Outcomes after hip or knee replacement surgery for osteoarthritis. Med. J. Aust. 1999, 171, 235-238. Available online: https:/ /www.mja.com.au/journal/1999/171/5/outcomesafter-hip-or-knee-replacement-surgery-osteoarthritis (accessed on 20 February 2017). [PubMed]

5. Ng, V.Y.; DeClaire, J.H.; Berend, K.R.; Gulick, B.C.; Lombardi, A.V. Improved Accuracy of Alignment with Patient-Specific Positioning Guides Compared with Manual Instrumentation in TKA. Clin. Orthop. Relat. Res. 2012, 470, 99-107. [CrossRef]

6. Cram, P.; Lu, X.; Kates, S.L.; Singh, J.A.; Li, Y.; Wolf, B.R. Total Knee Arthroplasty Volume, Utilization, and Outcomes Among Medicare Beneficiaries, 1991-2010. JAMA 2012, 308, 1227-1236. [CrossRef]

7. Ibrahim, M.; Alazzawi, S.; Nizam, I.; Haddad, F. An evidence-based review of enhanced recovery interventions in knee replacement surgery. Ann. R. Coll. Surg. Engl. 2013, 95, 386-389. [CrossRef]

8. Ibrahim, M.S.; Khan, M.A.; Nizam, I.; Haddad, F.S. Perioperative interventions producing better functional outcomes and enhanced recovery following total hip and knee arthroplasty: An evidence-based review. BMC Med. 2013, 11, 37. [CrossRef]

9. Munin, M.C.; Rudy, T.E.; Glynn, N.W.; Crossett, L.S.; Rubash, H.E. Early Inpatient Rehabilitation After Elective Hip and Knee Arthroplasty. JAMA 1998, 279, 847-852. [CrossRef]

10. Kucharzewski, M.; Mieszczański, P.; Wilemska-Kucharzewska, K.; Taradaj, J.; Kuropatnicki, A.; Śliwiński, Z. The Application of Negative Pressure Wound Therapy in the Treatment of Chronic Venous Leg Ulceration: Authors Experience. 2014. Available online: https:/ / www.ncbi.nlm.nih.gov/pmc/articles/PMC3947705/ (accessed on 11 August 2021).

11. Vuerstaek, J.D.D.; Vainas, T.; Wuite, J.; Nelemans, P.; Neumann, M.H.A.; Veraart, J.C.J.M. State-of-the-art treatment of chronic leg ulcers: A randomized controlled trial comparing vacuum-assisted closure (V.A.C.) with modern wound dressings. J. Vasc. Surg. 2006, 44, 1029-1037. [CrossRef]

12. Llanos, S.; Danilla, S.; Barraza, C.; Armijo, E.; Pieros, J.L.; Quintas, M.; Searle, S.; Calderon, W. Effectiveness of Negative Pressure Closure in the integration of split thickness skin grafts: A randomized, double-masked, controlled trial. Ann. Surg. 2006, 244, 700-705. [CrossRef]

13. Kamolz, L.-P.; Andel, H.; Haslik, W.; Winter, W.; Meissl, G.; Frey, M. Use of subatmospheric pressure therapy to prevent burn wound progression in human: First experiences. Burns 2004, 30, 253-258. [CrossRef]

14. Wanner, M.B.; Schwarzl, F.; Strub, B.; Zaech, G.A.; Pierer, G. Vacuum-Assisted Wound Closure for Cheaper and More Comfortable Healing of Pressure Sores: A Prospective Study. Scand. J. Plast. Reconstr. Surg. Hand. Surg. 2003, 37, 28-33. [CrossRef] [PubMed]

15. Stannard, J.P.; Gabriel, A.; Lehner, B. Use of negative pressure wound therapy over clean, closed surgical incisions. Int. Wound J. 2012, 9, 32-39. [CrossRef] [PubMed]

16. Siqueira, M.B.; Ramanathan, D.; Klika, A.K.; Higuera, C.A.; Barsoum, W.K. Role of negative pressure wound therapy in total hip and knee arthroplasty. World. J. Orthop. 2016, 7, 30-37. [CrossRef] [PubMed]

17. Huang, C.; Leavitt, T.; Bayer, L.R.; Orgill, D.P. Effect of negative pressure wound therapy on wound healing. Curr. Probl. Surg. 2014, 51, 301-331. [CrossRef] [PubMed]

18. Saxena, V.; Hwang, C.-W.; Huang, S.; Eichbaum, Q.; Ingber, D.; Orgill, D.P. Vacuum-assisted closure: Microdeformations of wounds and cell proliferation. Plast. Reconstr. Surg. 2004, 114, 1086-1096. [CrossRef] [PubMed]

19. Lancerotto, L.; Bayer, L.R.; Orgill, D.P. Mechanisms of action of microdeformational wound therapy. Semin. Cell. Dev. Biol. 2012, 23, 987-992. [CrossRef]

20. Miller, C. The history of negative pressure wound therapy (NPWT): From “Lip Service” to the Modern Vacuum System. J. Am. Coll. Clin. Wound Spec. 2012, 4, 61-62. [CrossRef]

21. Ubbink, D.T.; Westerbos, S.J.; Nelson, E.A.; Vermeulen, H. A systematic review of topical negative pressure therapy for acute and chronic wounds. Br. J. Surg. 2008, 95, 685-692. [CrossRef] 
22. Hudson, D.A.; Adams, K.G.; Van Huyssteen, A.; Martin, R.; Huddleston, E.M. Simplified negative pressure wound therapy: Clinical evaluation of an ultraportable, no-canister system. Int. Wound J. 2015, 12, 195-201. [CrossRef]

23. Sposato, G.; Di Caprio, G.; Scioli, M.; Ziccardi, P.; Molea, G.; La Rusca, I. Ambulant vacuum-assisted closure of skin-graft dressing in the lower limbs using a portable mini-VAC device. Br. J. Plast. Surg. 2001, 54, 235-237. [CrossRef]

24. Single Use Negative Pressure Wound Therapy NPWT I Smith \& Nephew-Corporate. Available online: http:/ / www.smithnephew.com/key-products/advanced-wound-management/pico/ (accessed on 11 August 2021).

25. Karlakki, S.L.; Hamad, A.K.; Whittall, C.; Graham, N.M.; Banerjee, R.D.; Kuiper, J.H. Incisional negative pressure wound therapy dressings (iNPWTd) in routine primary hip and knee arthroplasties. Bone Jt. Res. 2016, 5, 328-337. [CrossRef]

26. Surgical Site Infections: Prevention and Treatment | 2-Research-Recommendations | Guidance and Guidelines | NICE. Available online: https://www.nice.org.uk/guidance/cg74/chapter/2-research-recommendations (accessed on 21 February 2017).

27. Sculco, T.P. The economic impact of infected total joint arthroplasty. Instr. Course Lect. 1993, 42, 349-351.

28. Segawa, H.; Tsukayama, D.T.; Kyle, R.F.; Becker, D.A.; Gustilo, R.B. Infection after total knee arthroplasty. A retrospective study of the treatment of eighty-one infections. J. Bone Jt. Surg. Am. 1999, 81, 1434-1445. [CrossRef]

29. Meehan, J.P.; Danielsen, B.; Kim, S.H.; Jamali, A.A.; White, R.H. Younger age is associated with a higher risk of early periprosthetic joint infection and aseptic mechanical failure after total knee arthroplasty. J. Bone Jt. Surg. Am. 2014, 96, 529-535. [CrossRef] [PubMed]

30. Bongartz, T.; Halligan, C.S.; Osmon, D.R.; Reinalda, M.S.; Bamlet, W.R.; Crowson, C.S.; Hanssen, A.D.; Matteson, E.L. Incidence and risk factors of prosthetic joint infection after total hip or knee replacement in patients with rheumatoid arthritis. Arthritis Care Res. 2008, 59, 1713-1720. [CrossRef] [PubMed]

31. Wound Healing in Total Joint Replacement I The Bone \& Joint Journal. Available online: http:/ / www.bjj.boneandjoint.org.uk/ content/95-B/11_Supple_A/144.long (accessed on 18 February 2017).

32. Galat, D.D.; McGovern, S.C.; Larson, D.R.; Harrington, J.R.; Hanssen, A.D.; Clarke, H.D. Surgical Treatment of Early Wound Complications Following Primary Total Knee Arthroplasty. J. Bone Jt. Surg. 2009, 91, 48-54. [CrossRef]

33. Whitehouse, J.D.; Friedman, N.D.; Kirkland, K.B.; Richardson, W.J.; Sexton, D.J. The Impact Of Surgical-Site Infections Following Orthopedic Surgery at a Community Hospital and a University Hospital Adverse Quality of Life, Excess Length of Stay, and Extra Cost. Infect. Control. Amp. Hosp. Epidemiol. 2002, 23, 183-189. [CrossRef] [PubMed]

34. Lawrence, J.C. Dressings and wound infection. Am. J. Surg. 1994, 167, S21-S24. [CrossRef]

35. Patel, V.P. Factors Associated with Prolonged Wound Drainage After Primary Total Hip and Knee Arthroplasty. J. Bone Jt. Surg. Am. 2007, 89, 33. [CrossRef] [PubMed]

36. Howell, R.D.; Hadley, S.; Strauss, E.; Pelham, F.R. Blister formation with negative pressure dressings after total knee arthroplasty. Curr. Orthop. Pract. 2011, 22, 176. [CrossRef] 